\title{
Engineering Critical Assessment for Offshore Pipeline with Semi Elliptical Surface Cracks in Girth Weld - Comparison of FEM and BS7910 Guideline
}

\section{Seyed Mohammad Hossein Sharifi ${ }^{1 *}$, Seyed Reza Soheili ${ }^{2}$, Ali Shaghaghi Moghaddam ${ }^{3}$, Farhood Azarsina ${ }^{4}$}

${ }^{I}$ Assistant Professor, Faculty of marine science, Petroleum University of Technology, Mahmoudabad, Iran; Sharifi@put.ac.ir

${ }^{2}$ MSc. Offshore Structure Engineering, Science and Research Branch, Islamic Azad University, Tehran, Iran; Reza.soheili@srbiau.ac.ir

${ }^{3}$ Assistant Professor, Department of Mechanical Engineering, Islamic Azad University, Takestan Branch, Iran; Shaghaghi@ioec.com

${ }^{4}$ Assistant Professor, Department of Marine structure, Science and Research Branch, Islamic Azad University Tehran,Iran; F.Azarsina@srbiau.ir

\section{ARTICLE INFO}

Article History:

Received: 14 Mar. 2018

Accepted: 2 Sep. 2018

Keywords:

Engineering Critical Assessment

Offshore Pipeline Girth weld

Surface cracks

Acceptance Criteria

FEM

\begin{abstract}
Economical design with sufficient fracture resistance is of high importance in any offshore pipeline projects. Using an Engineering Critical Assessment (ECA), alternate acceptance criteria for pipeline girth weld inspection can significantly reduce the cost of constructing of offshore oil and gas pipeline by minimizing unnecessary repairs. Offshore pipelines consist of short pipeline segments connected by girth welding method. Surface and embedded elliptical cracks due to welding operation are often observed at welding zone which pose a potential threat to the reliability of the offshore pipelines. To derive the acceptance criteria for pipeline girth weld defects and pipeline safety during installation and operation phase, an ECA based on fracture mechanics is required. In this paper, ECA of offshore pipeline with semi elliptical surface crack under pure tension loading is performed according to finite element method and BS7910 guideline. Moreover, a comparison between these two methods is offered. It is concluded that, ECA by BS7910 guideline is more conservative than finite element method, and the difference between the two diagrams increases as strain levels are increased. Also, comparisons of critical crack size curve for various strain levels are studied.
\end{abstract}

\section{Introduction}

The demand for long distance offshore pipeline of natural oil and gas transportation is increasing; hence, it is of great significance to ensure the structural integrity of pipeline, during both installation and operation [1]; consequently a bunch of recent research has placed an emphasis on the reliability of offshore pipelines due to potential defects such as cracks in girth weld.

Offshore pipelines usually consist of many kilometers of girth weld; thus, the likelihood of potential defects must be taken into account during design [1]. Surface cracks may occur as result of welding defects, corrosion, etc. in pipeline. They are common in girthwelded pipes and pose major challenges to structural integrity assessments.

In the present industry, Engineering Critical Assessment is defect acceptance criterion based on fracture mechanics. Utilizing an ECA alternative acceptance criteria for pipeline girth weld can significantly reduce the cost of installation of offshore pipeline by minimizing repairs.

ECA permits engineers to evaluate a pipeline containing imperfection for expected service condition or fitness for purpose (FFP).The use of high strength steels, which provides cost savings, increases the importance of fracture mechanics in the design of pipelines [2].Fracture mechanics based assessment methods are usually used to present flaw acceptance criteria for girth weld in offshore pipelines [3].

A general method widely used in the pipeline industry, especially according to the assessment of girth welds, is BS 7910 [4]. Most fracture mechanics procedures that are used to assess offshore pipeline girth weld are stress-based, although the limitations are often represented in terms of strain. For example, API 1104 
[5] Appendix A, limits stress-based assessment to $0.5 \%$ strain and DNV OS F101 [6], Appendix A to 0.4\% strain. This means that the stress-based methods are not appropriate when the applied stress exceeds the yield strength of the pipeline. For many pipeline installation methods, the applied longitudinal stress is below the defined minimum yield strength. However, there are various installation systems, such as reeling method, which are used for offshore pipeline, where the pipeline is subjected to large plastic straining often involving more than one cycle [7].

Strain-based fracture mechanics assessment procedure is applied when the axial strain on the pipe exceeds the yield strain of the pipe material. Strain-based methods are significantly more complex than stress based methods [8].

By improving in computer science, many researches had been done by finite element method, to estimate crack driving force in form of J-integral or CTOD. Crack Tip Opening Displacement test or CTOD is one of a family of fracture mechanics tests that measures the resistance of a material to growing cracks and $\mathrm{J}$ integral is extensively used in fracture mechanics as an energy-based criterion for determining the onset of crack growth.

As an effort for these research Wang et al. [9] presented a three-region design diagram as a conceptual description of the strain design methodology. The comparison of the developed strain-based method with full-scale test data reveals that the criteria are almost always conservative in the case of lower bound fracture toughness. With some modifications, a new reference stress solution was proposed by Tkaczyk et al. [10] which is more appropriate for use in the offshore industry. Although the approach had improvement in results but it still does not have efficiency for a strainbased formulation.

In the work of Taheri and Nourpanah [11], a strainbased formulation is developed in order to fracture assessment of reeled pipelines. They tried to improve the "reference strain" approach of Linkens et al. [12]. This approach can handle large plastic deformations for predicting fracture response of pipes for specific cracks and materials. Recently Yi et al. [13] studied the behavior of the flawed pipeline girth weld with large defects subjected to a large tension load and proposed an empirical formula for crack driving force estimation in the form of CTOD.

As an extension, Zhang et al. [14] employed a large bending moment as well as bending and internal pressure to the pipeline girth weld with large but semielliptical surface and also elliptical embedded crack, providing a CTOD estimation value for each of them.

The nonlinear elastic plastic fracture response of pipeline girth weld with embedded cracks is investigated through 3-D finite element analysis combined with submodels technique. Strain-based estimation formulas for crack tip opening displacement are proposed for the pure bending load as well as the bending combined with the internal pressure in 2015 by Zhang et al. [14].

Current codes and standards for fracture assessment of offshore pipelines provide only an incomplete description and are proved to be too conservative in use [2] since they are mostly derived from load-controlled methodology. Accordingly, strain-based approach has been approved for fracture assessment of offshore pipeline when the yield strength is significantly exceeded [15]. In the 1990s, a strain-based estimation on CTOD and J-integral was proposed by Schwalbe [16] for small strain levels. They require more input in terms of material properties, loading data and assessment. Use of the three dimensional elastic plastic Finite Element Analysis (FEA) is sometimes followed up with full scale validation testing.

This paper performs ECA of offshore pipeline with both finite element (FE) and BS7910 guideline method. A methodology is described using the FE-based program ZENCRACK [17] for ECA analysis. ZENCRACK is a state of the art software tool for 3D finite element simulation and CRACKWISE [18] software is used for analysis-based BS7910 guideline. Also, a comparison is made between these two methods.

\subsection{BS7910 guideline}

British Standards Institution set up a logical acceptance standard which was both safer and more economical than the traditional workmanship acceptance standards. In BS 7910 [4], there are three levels, available for a fracture assessment. The Level 1 which is called simplified assessment procedure is based on a conservative Failure Assessment Diagram (FAD) applicable when the data on the materials properties is limited. The Level 1 FAD has $\mathrm{Kr}, \mathrm{Sr}$ co-ordinates, where $\mathrm{Kr}$ is the ratio of applied crack driving force to fracture toughness and $\mathrm{Sr}$ the ratio of applied stress to flow strength where the flow strength is mean of yield and tensile strength hence including some plasticity. For the cases where single-value measurements of fracture toughness are available level 2 is used, which is named normal assessment method. Further, there are two assessment strategies: Level 2A and Level 2B. When material specific full stress-strain information is available, Level 2B is utilized based on reference stress solution. Level 3 is similar to level 2 with the exception that is appropriate for ductile materials showing tearing mode of failure with Level 3A and 3B depending on the type of stress-strain data available. A typical figure of FAD is shown in Fig 1. 


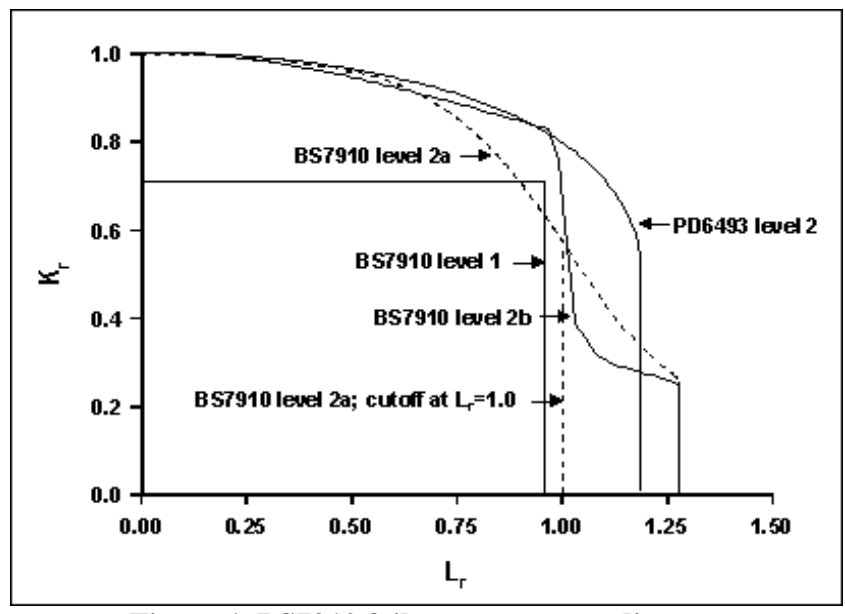

Figure 1. BS7910 failure assessment diagram

According to BS7910 level 2B, a flaw can be accepted when the following equation is satisfied:

$\mathrm{K}_{\mathrm{r}} \leq\left(\frac{\mathrm{E} \varepsilon_{\mathrm{ref}}}{\sigma_{\mathrm{ys}} \mathrm{L}_{\mathrm{r}}}+\frac{\mathrm{L}_{\mathrm{r}}^{3} \sigma_{\mathrm{ys}}}{2 \mathrm{E} \varepsilon_{\mathrm{ref}}}\right)^{-1 / 2}$

Where in Eq.(1) $K_{r}=K_{I} / K_{\text {mat }}$ is fracture ratio, $\sigma_{\text {ref }}$ is reference stress, $\varepsilon_{\text {ref }}$ is the true strain obtained from the uni-axial tensile stress-strain curve at reference stress, $\mathrm{L}_{\mathrm{r}}=\sigma_{\text {ref }} / \mathrm{YS}$ is load ratio, and $\mathrm{E}$ is the Young's modulus. The first term in Equation (1) considers both the limiting elastic and fully plastic behaviors. The second term determines the response in between these two limits where the general behavior is elastic but fracture parameter exceeds its elastic value, and a minor plasticity correction is supply by this term [19]. In this paper CRACKWISE is used to compute multiple parametric equations, calculation of limiting conditions (for example, the maximum tolerable flaw size in a structure under given conditions), reporting, editing and archiving such complex calculations.

\section{Methodology}

This approach is designed for deciding acceptability of flaws found by ultrasonic testing where information on height, position through the pipe wall thickness, as well as length are provided. The potential benefits of this method are a reduction in costs by minimizing the need for repair and delay imposed. Furthermore, the ECA is also used to evaluate the acceptable flaw size in existing structures.

Hence, it can be said that ECA is carried out through all the phases of pipeline's life cycle from the installation until the end of the design life

The methodology of ECA assessment is based on determining maximum acceptable defect sizes after pipeline welding procedure that are permitted to take place in girth welds under specific loading without violating the fracture toughness. Any defects under allowable limit, which are detected in the Automatic Ultrasonic Test (AUT) procedure, are not believed to develop unstable fracture during installation and/or operational design loading phases.

\subsection{Geometrical Configuration}

The geometrical configuration of semi elliptical surface crack in offshore pipeline is shown in Fig 2 in which a is crack depth, and $2 \mathrm{c}$ is circumferential crack length. The outer diameter of pipeline is $406.4 \mathrm{~mm}$, and the average wall thickness is $24 \mathrm{~mm}$. A surface cracked pipe with outer diameter, D and wall thickness, t, were considered in this study. The surface cracks are usually modelled as elliptical in the literature. However, the shape of the crack is not expected to significantly influence the fracture parameters at the center of the crack, where the maximum $\mathrm{CTOD} / \mathrm{J}$-integral is observed.

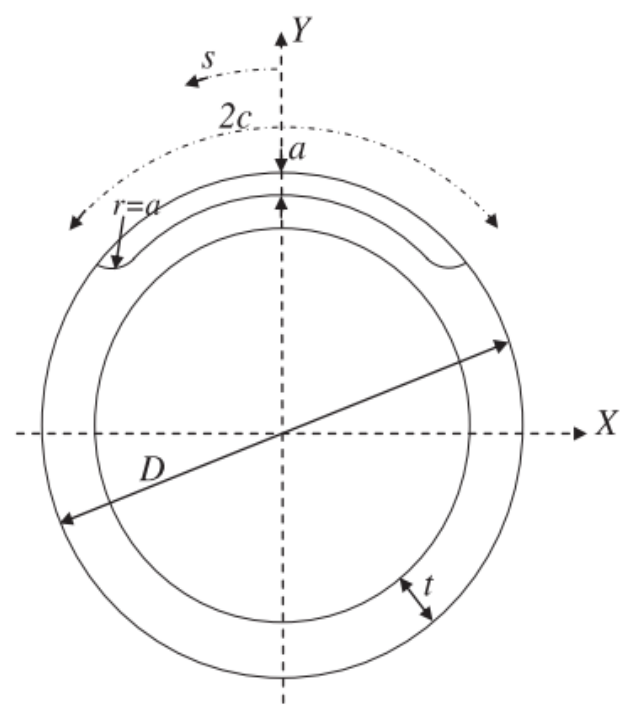

Figure 2. The geometrical configuration of the surface crack

\subsection{Fracture Toughness}

According to DNV-RP-F108 [20], the objective of the fracture resistance test is to determine the fracture resistance for both the pipe and girth welds to calculate the acceptable flaw sizes.

DNV-RP-F108 recommended conducting the fracture test by using the SENT (Single Edge Notched

Tension) specimen. The critical CTOD for X65 pipe is considered 0.45 .

\section{Modeling}

In this study, first the ECA analysis is performed based on BS7910 guideline through CRACKWISE software and then ECA analysis is performed based on finite element method through ABAQUS [21] and ZENCRACK software. Primary modeling has been done through ABAQUS software to apply loading scenario and design geometry of pipe, then the model imported in ZENCRACK software to generate mesh around the crack area. To demonstrate the potential for direct calculations, the crack driving force for ECA was calculated for a pipe loaded in tension. CTOD was calculated according to finite element method, and the failure assessment diagram was compared with BS7910 guideline. 


\subsection{Material properties}

Material properties are shown in Table 1, in which YS is yield stress, UTS is ultimate tensile stress, E is the Young's modules, and $\vartheta$ is Poisson's ratio.

API 5L Grade X65 is adopted for the pipe. And the weld metal and parent metal are considered as even match situation. The isotropic power-law hardening is adopted to characterize the steel material behavior, expressed as below

$$
\sigma= \begin{cases}E \varepsilon & \varepsilon \leq \varepsilon_{Y} \\ \sigma_{\mathrm{Y}}\left(\frac{\varepsilon}{\varepsilon_{\mathrm{Y}}}\right)^{\mathrm{n}} & \varepsilon>\varepsilon_{\mathrm{Y}}\end{cases}
$$

Where $\sigma_{Y}$ is the yield stress, $\varepsilon_{Y}=\sigma_{Y} / E$ is the corresponding yield strain, $\mathrm{E}$ is Young's modulus and $\mathrm{n}$ is the strain hardening exponent usually obtained through fitting experimental stress-strain data. Based on the experimental data provided by DNV [6], $\mathrm{n}$ is set as 0.05 and 0.26 for the carbon steel. The length of the pipe is considered three times as long as the outer diameter [22].

Table 1. Material properties

\begin{tabular}{ll}
\hline Characteristic & Value \\
\hline YS $($ MPa) & 545 \\
\hline UTS $(\mathrm{MPa})$ & 592 \\
\hline E (GPa) & 207 \\
\hline$\vartheta$ & 0.3 \\
\hline
\end{tabular}

\subsection{Loading Scenarios}

Installation of offshore pipelines introducing large plastic strains has proven to be cost efficient in many projects. As the installation process subjects the pipe and girth welds to large repeated plastic straining fracture of the girth welds during installation, it can turn into a potential failure mode. Consequently, it needs to be assured that the pipeline has adequate resistance against growth of defects both by stable tearing and unstable fracture during installation as well as during the subsequent service.

The evolution of offshore pipeline with an external circumferential surface crack is investigated under pure tension loading. The pipe was loaded in tension by specifying a fixed displacement at the un-cracked end of the pipe (Fig 3).

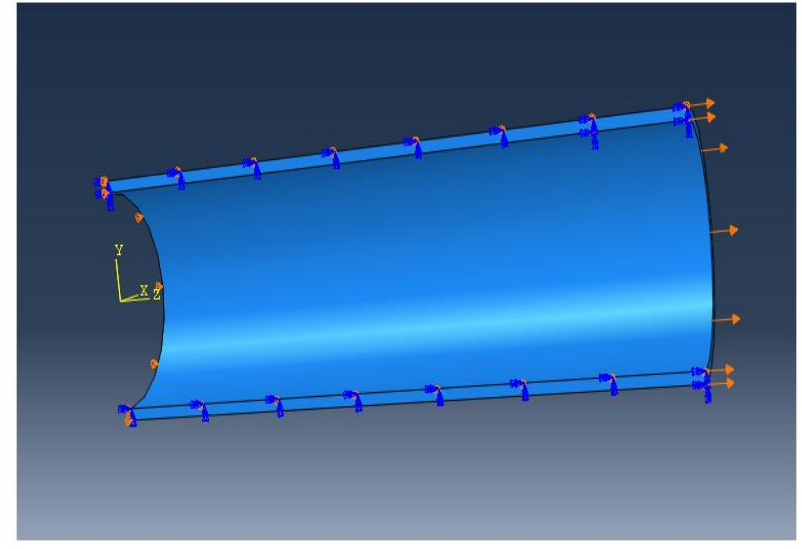

Figure 3. Fixed displacement at the un-cracked end of the pipe

Considering symmetry, only one-quarter of the pipe was modeled. This boundary condition is also called $\mathrm{X}$-symmetry. The pipe was subjected to uniform tension.

\subsection{BS7910 Guideline method}

The ECA analyses in current study are carried out using level 2 procedures according to BS9710 with specific material stress-strain curve which means that type B of levels 2 and 3 are used. Level 2 is the normal assessment method whilst, Level 3 is capable of modeling ductile tearing based on toughness expressed in terms of an R-curve. The stresses that will be considered in the analysis are primary and secondary stresses. The primary stress is the one that could contribute to plastic collapse. It includes all stresses appearing from internal pressure and external loads. Thermal and residual stresses are usually classified as secondary stresses. A significant characteristic of secondary stresses is that they do not lead to plastic collapse. However, both primary and secondary stresses can contribute to failure by fracture. BS7910 provides guidance on methods for analyzing the consequence of defects in terms of the structural integrity of welded structures. The methods are based on fracture mechanics.

\subsection{Finite Element Method}

ZENCRACK is a state of the art software tool for 3D fracture mechanics simulations in a timely and cost effective manner. Fracture mechanics parameters such as J-Integral or CTOD which is achieved by automatic generation of focused mesh for cracked finite element meshes from un-cracked finite element models is calculated. Analysis will start with the maximum crack height and then the iteration begins to find the critical crack length that satisfies the acceptance criteria for the given crack length.

The method used by finite element to generate a cracked mesh is the replacement of one or more brick elements in an un-cracked mesh by crack-blocks. In other words, each crack-block replaces one element for 
un-cracked mesh. The term crack-block refers to a collection of brick elements stored as a unit cuboid. Complete crack front in a mesh may be defined by one crack-block or a series of connected crack-blocks depending on modeling requirements. The elements around the crack front are arranged in rings in order to provide a focused mesh around the crack front. Fig.4 shows a crack-block that is used in modeling.

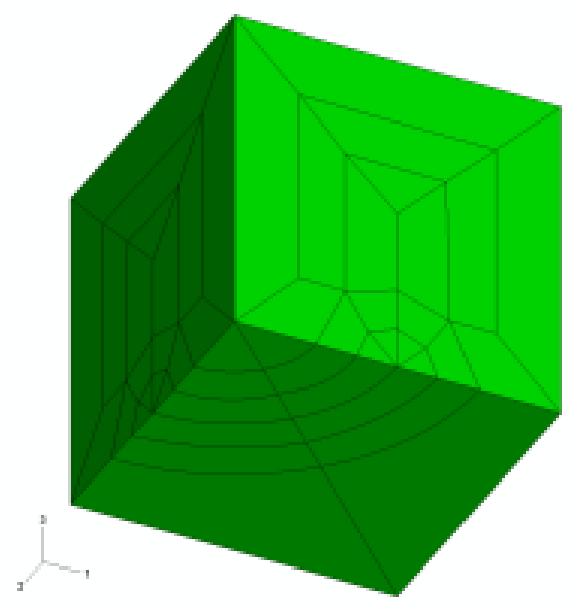

Figure 4. Standard quarter circular crack block [17]

In this analysis, crack growth is not involved, so the application of standard crack-blocks significantly reduces the analysis time with no cost to the accuracy. Fig. 5 shows a sample finite element model and crack situation and close-up of the near-tip mesh.

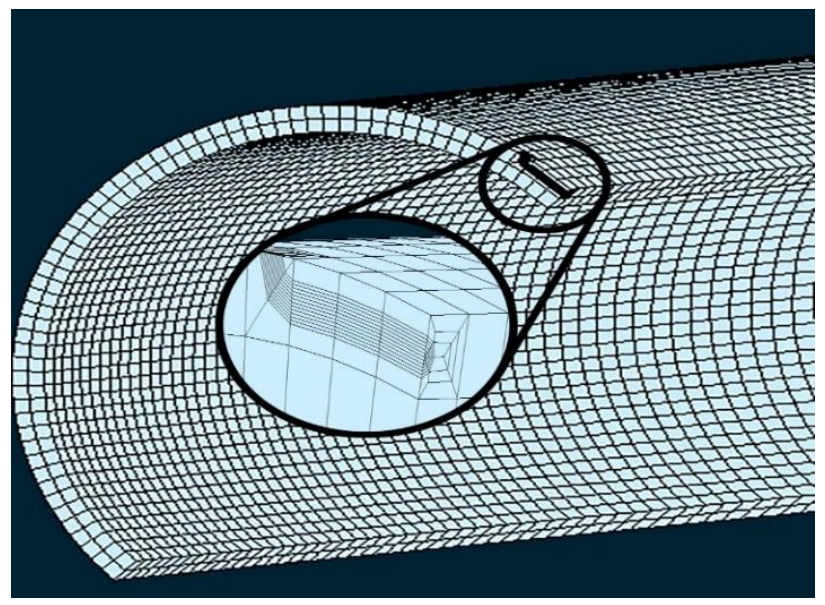

Figure 5. Typical finite element mesh employed for modeling the cracked pipe and Details of the mesh near the crack region

After meshing, the analysis is performed and CTOD value is achieved. To compare the CTOD with critical value, the critical crack size curve will be obtained.

\section{Results and Discussion}

The purpose of this study is to demonstrate the potential for direct calculation. The crack driving force for Engineering Critical Assessment has been calculated for a pipe loaded in tension. All parameters were kept constant except loading (three levels of strain; $0.3 \%, 0.8 \%, 1.2 \%$ ) and crack size to derive critical crack size curve at three levels of strain. Finally, numerical analysis using finite element were carried out to be compared with the analytical analysis using BS7910 guideline. This section presents results of the analysis carried out for the ECA of pipeline girth welds. At first, ECA analysis is performed based on BS7910 [4] (the guideline for assessing acceptability of flaws in steel structures), after that ECA analysis is performed via direct finite element method.

Critical crack size curves are presented according to BS7910 guideline level 2B. At level 2B, cracks are assumed to be not propagate. Each curve represents specific strain level including $0.3 \%, 0.8 \%$ and $1.2 \%$.

\subsection{Validation of finite element method}

Finite element results are validated with full scale experimental tests through Wang et al. [23] investigations at Pipeline Research Council International (PRCI).The experimental test is for X65 pipe and $323.85 \mathrm{~mm}$ outer diameter and $12.7 \mathrm{~mm}$ wall thickness. According to Fig. 6, the experimental and finite element results of Tensile Strain Capacity are approximately close to each other.

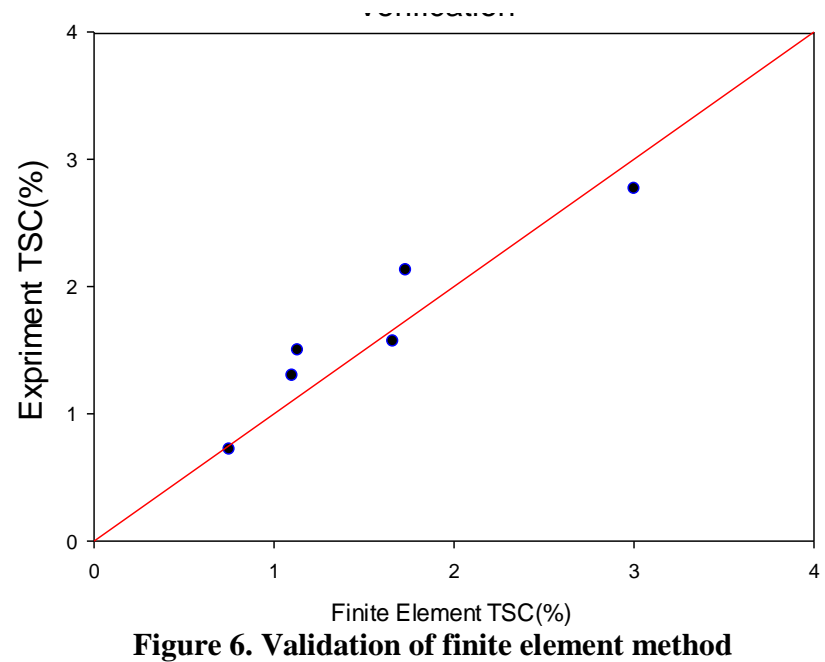

\subsection{BS7910 guideline based results}

Tolerable defect size curves are presented according to BS7910 guideline level 2B.

In Fig. 7, critical crack size curve for offshore pipeline under installation loading are shown. Each curve specifies the safe and unsafe region for cracks that are found in a pipeline. 


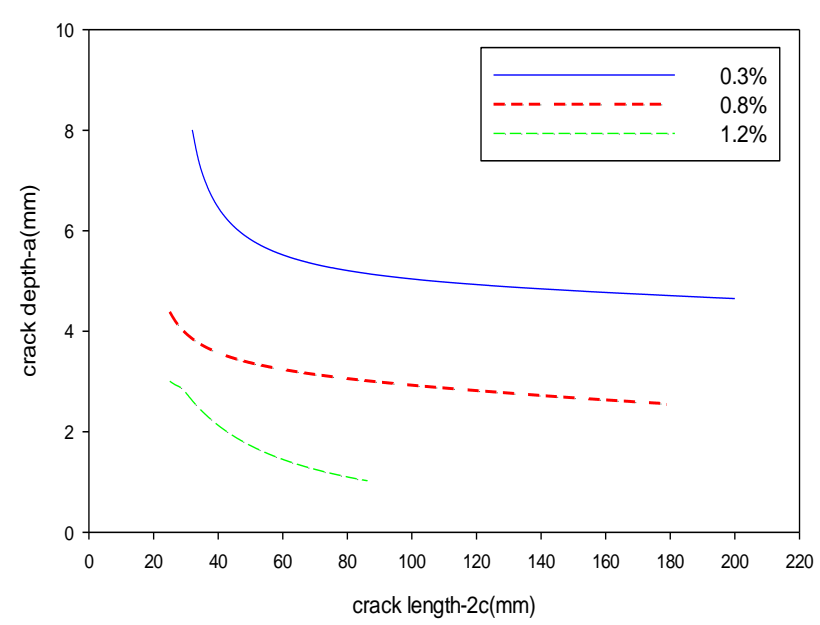

Figure 7. Critical crack size curve according to BS7910-based method for three levels of strain $(0.3 \%, 0.8 \%, 1.2 \%)$ for 16 "pipe and $24 \mathrm{~mm}$ wall thickness

Fig. 7 depicts the critical crack size curve for a 16" pipe and $24 \mathrm{~mm}$ wall thickness under $0.3 \%, 0.8 \%$ and $1.2 \%$ of strain levels.

As shown in graphs, at $0.3 \%$ strain level, there is a severe slope for short cracks and a gentle slope for long cracks. According to the graph, we can say that the crack depth has more effects on the short cracks as compared to the long ones.

At $0.8 \%$, by increasing in the crack length, we have reduced in allowable crack depth.

The curve data for crack length is from $20 \mathrm{~mm}$ to 180 $\mathrm{mm}$, and the crack depth has changed from $4.5 \mathrm{~mm}$ to $2.5 \mathrm{~mm}$.

As loading level is increased, diagram slope in short and long cracks seems almost uniform and crack depth does not have an especial effect on larger strain.

Also, the comparison of three levels of loading for similar crack length shows that, 266 percent increase in the loading level, result in 180 percent reduction in allowable a/t. This reduction is augmented to 225 percent when the loading level is increased by 400 percent.

The area below the graphs shows the safe region for cracks that are found in the pipeline. Four hundred percent increase in loading level led to 900 percent reduction in the safe area for BS7910 guideline results.

\subsection{FE based results}

To demonstrate the potential of direct calculations, the crack driving force for Engineering Critical Assessments has been calculated for a pipe loaded in tension. Critical crack size curves are presented through finite element method. Fig. 8, shows critical crack size curve for offshore pipeline under installation loading. Each curve specifies the safe and unsafe region for cracks that are found in a pipeline.

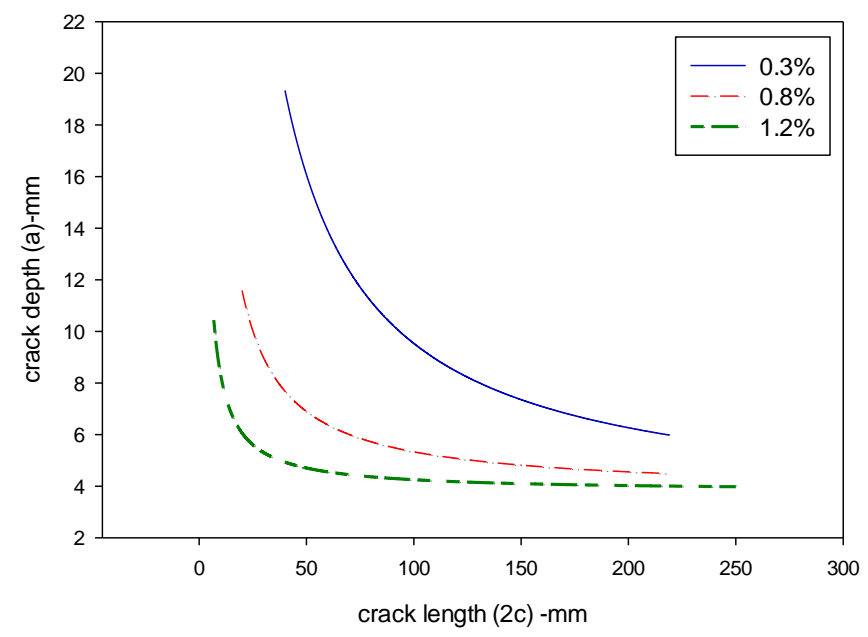

Figure8. Critical crack size curve according to FE based method for three strain levels $(0.3 \%, 0.8 \%, 1.2 \%)$ for 16 "pipe and $24 \mathrm{~mm}$ wall thickness

As the crack length is increased, we observe reduction in allowable crack depth. This reduction in short cracks region is more severe than long cracks region.

At $0.8 \%$ strain level, critical crack size curve shows that the safe region for cracks is more limited than that for cracks at $0.3 \%$ strain level. In this curve, we have also a severe slope in shorter cracks and as the crack length is increased, the slope curve is reduced.

At $1.2 \%$ strain level, up to $60 \mathrm{~mm}$ crack length, we see a large change in critical crack size curve. However, after that the curve slope exhibits a steady reduction. By comparing the area below the graphs, it can be found that 400 percent higher loading level resulted in 180 percent lower area below the graphs that represents the safe region for cracks.

Another study that is performed in this paper is ECA for a 32" pipe with $24 \mathrm{~mm}$ wall thickness. In Fig. 9 depicts critical crack size curve for three strain levels. It is clearly shown that by increasing strain level, the region below the graphs that indicates the safe cracks are reduced.

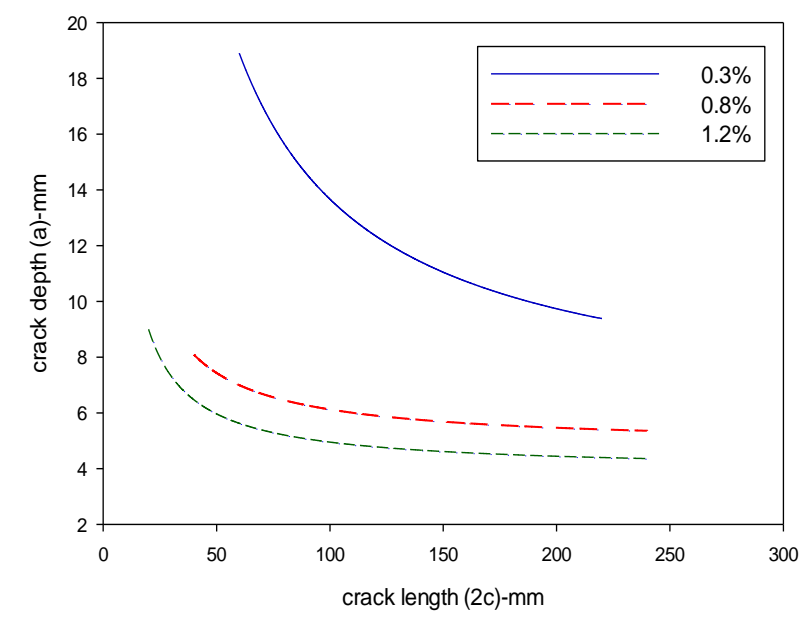

Figure9. Critical crack size curve according to $\mathrm{FE}$ based method for three strain levels $(0.3 \%, 0.8 \%, 1.2 \%)$ for 32 " pipe and $24 \mathrm{~mm}$ wall thickness 


\subsection{Comparison between FE method and BS7910 guideline}

A comparison between critical crack size curve from finite element method and BS7910 guideline method is performed and the differences between the two methods are shown in Figs. 10, 13 and 14. By comparing the finite element method curve results with BS7910 guideline-based method, it can be concluded that in every strain level, the BS7910 guideline-based method is conservative.

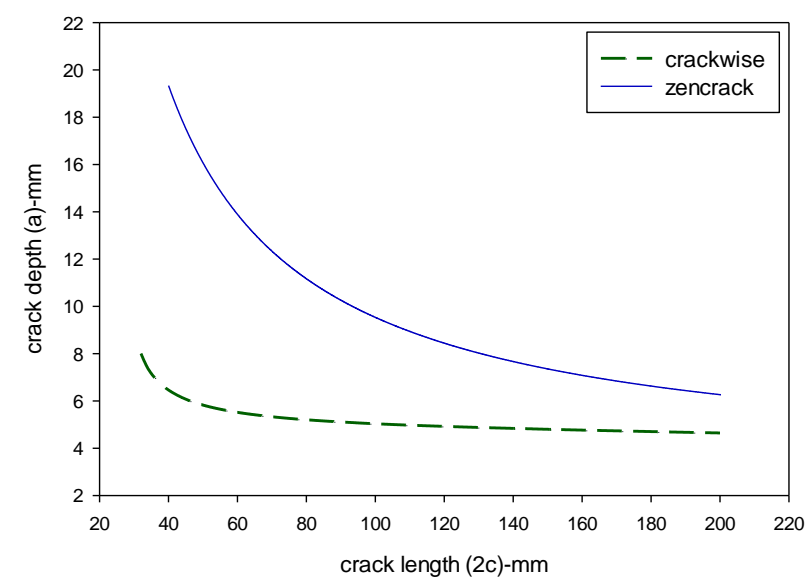

Figure10. Comparison of BS7910 guideline and FE method at $\varepsilon=0.3 \%$

The comparison of these two methods at $0.3 \%$ strain reveals that for a similar crack length in short crack region, for example $2 \mathrm{c}=60 \mathrm{~mm}$, the allowable crack depth, according to BS7910 and finite element is 5.5 $\mathrm{mm}$ and $13.9 \mathrm{~mm}$, respectively and this value for the $2 \mathrm{c}=165 \mathrm{~mm}$ goes to $4.7 \mathrm{~mm}$ and $6.9 \mathrm{~mm}$ for BS7910 and finite element results, respectively. The results also show that at $0.3 \%$ strain, with the increase in crack length, the difference between the two methods starts to diminish.

The critical crack size curve, according to BS7910 guideline and FE method for $0.8 \%$ strain level is shown in Fig.11.

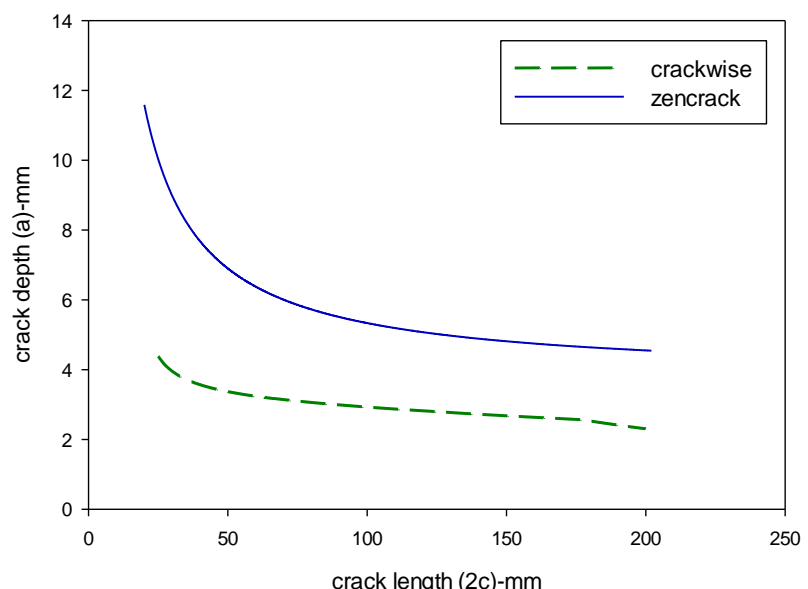

Figure11. Comparison of BS7910 guideline and FE method at $\varepsilon=0.8 \%$
It shows that the allowable crack depth for whole range of crack length for BS7910 guideline-based graph is lower than FE method.

The critical crack size curve for a 16" pipe and $24 \mathrm{~mm}$ wall thickness under 1.2\% strain is presented in Fig. 12. It clearly shows that higher strain level and loading deepen the difference between the two diagrams.

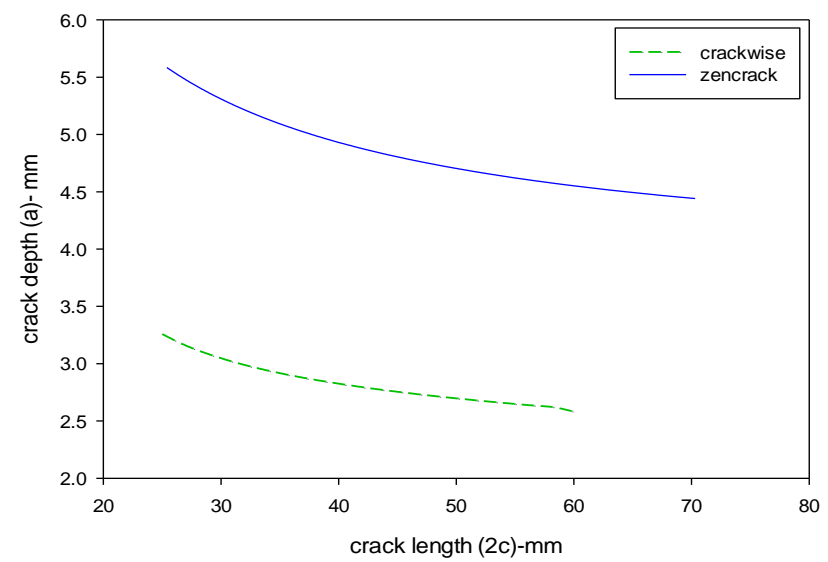

Figure12. Comparison of BS7910 guideline and FE method at $\varepsilon=1.2 \%$

The BS7910 and finite element curves differ by 177 percent at this level of loading. It can be seen in Fig.14 that the BS7910-based method is more conservative than the finite element method. This proposition is confirmed by Thaulow et al. [2] too. They performed a study in 2005 in that the line-spring calculations are compared with 3-D FE calculations and computations according to BS7910 guideline. They presented CTOD-Applied Strain diagram. Their results show that for all cases, BS7910 guideline is more conservative than other method. Their graph for 30\% crack length of the circumference (Fig. 13) shows that for long crack, BS7910 guideline results differ considerably with the results of LINKpipe and ABAQUS after $0.2 \%$ strain level.

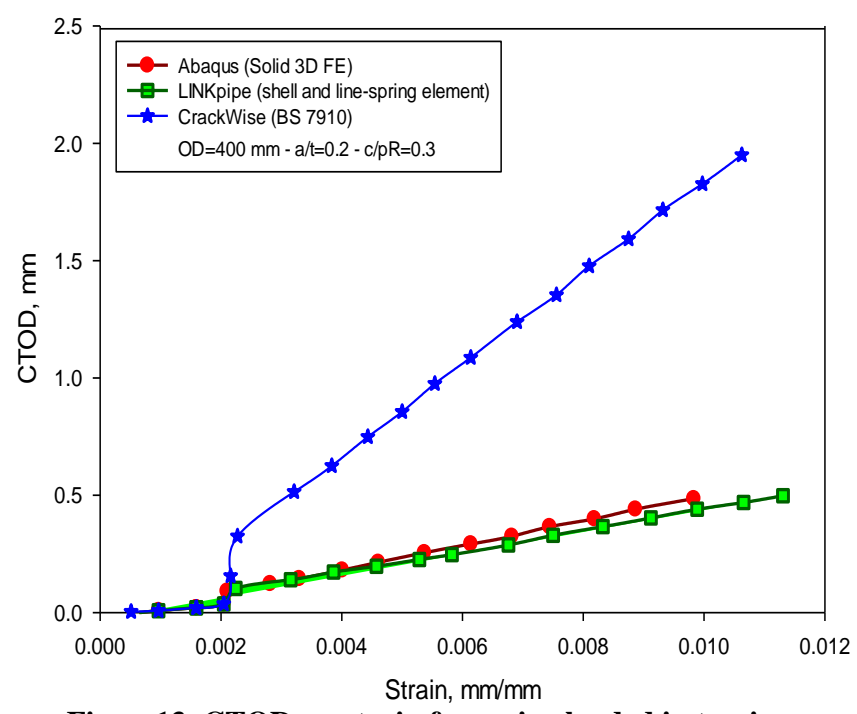

Figure13. CTOD vs. strain for a pipe loaded in tension. Comparison between line-spring (LINKPIPE), 3-D and analytical (BS7910/CRACKWISE) calculations. 


\section{Conclusions}

The present paper offers an investigation to use an efficient and accurate method for fracture assessment of offshore pipelines with semi elliptical surface crack under pure tension loading. Finite element and BS7910 guideline-based analysis has been carried out to obtain critical crack size curve.

The followings are the main conclusions of the study: BS7910 results show that for similar crack lengths, 266 percent increase in the loading level brings about a 180 percent reduction in allowable a/t. This is 225 percent reduction when the loading level is increased by 400 percent. It also shows the stronger effect for crack depth against crack length on critical crack size curve in short crack region at all three strain levels.

In the case of 32" and 16" pipe results, it is clearly shown that when strain level is increased, the region below the graphs that indicates the safe cracks is reduced.

By comparison of the BS7910 guideline-based method and FE method, it can be concluded that higher strain level and loading deepen the difference between the two diagrams. The difference between two methods is deeper at short crack length than at long crack length. Generally, BS7910 guideline-based method is more conservative than finite element-based method.

\section{References}

1- Berg, E., Ostby, E., Thaulow, C., (2008), Ultimate fracture capacity of pressurized pipes with defects Comparisons of large scale testing and numerical simulations, Engineering Fracture Mechanics, vol. 75, no. 8 , pp. 2352-2366.

2- Thaulow,C., Jayadevan, K.R, (2005), Fracture Control Offshore Pipelines - Advantages of using direct calculations in fracture assessments of pipelines, 24th International Conference on Offshore Mechanics and Arctic Engineering (OMAE 2005), halkidiki.

3- Pisarski, H., (2013), Assessment of flaws in pipeline girth welds - a critical review, TWI.

4- BS7910, (2005), Guide to methods for assessing the acceptability of flaws in metallic structures, British Standard.

5- API,. (1999), American Petroleum Institute, Standard for Welding Pipelines.

6- DNV, (2012), Submarine Pipeline Systems.

7- Zhang, Y.M., Xiao, Z.M., Zhang, W.G., (2013), On

3-D crack problems in offshore pipeline with large plastic deformation, Theoretical and Applied Fracture Mechanics, Vols. 66-67, pp. 22-28.

8- Linkense, D., Formby,CL., (2000), A strain-based approach to fracture assessment, 5th International Conference on Engineering.

9- Wang,YY., Stephens, M., Horsley,D., (2008), Preliminary analysis of tensile strain capacity of fullscale pipe tests with internal pressure. 18th
International offshore and polar engineering conference ISOPE. Vancouver, British Columbia, Canada

10- Tkaczyk, T., O’Dowd, N. P., Nikbin, K., (2009), Fracture assessment procedures for steel pipelines using a modified reference stress solution. ASME International Journal of Pressure Vessels and Piping, vol. 131

11- Nourpanah, N., Taheri, F., (2010), Development of a reference strain approach for assessment of fracture response of reeled pipelines. Journal of Engineering fracture mechanics, vol 77: p. 2337-2353.

12- Linkens D, Formby CL, Ainsworth RA. A (2000). Strain-based approach to fracture assessment-example applications. Proceedings of fifth international conference on engineering structural integrity assessment. Cambridge: EMAS.

13- Yi, D. K., Sridhar, I., Zhongmin, X., Kumar, S. B., (2012). Fracture capacity of girth welded pipelines with 3D surface cracks subjected to biaxial loading conditions. International Journal of Pressure Vessels and Piping, vol. 92, no. 11, p. 115-126.

14- Zhang, Z., Yi, D., Xiao, Z., Huang, Z., (2015), Engineering critical assessment for offshore pipelines with 3-D elliptical embedded cracks, Engineering Failure Analysis journal, vol. 51, pp. 37-54.

15- Berg, E., Skallerud, B., Thaulow, C., (2008), Twoparameter fracture mechanics and circumferential crack growth in surface cracked pipelines using linespring elements, Engineering Fracture Mechanics, vol. 75, no. 1, pp. 17-30.

16- Schwalbe, K., (1994), The crack tip opening displacement and $\mathbf{J}$ integral under strain control and fully plastic conditions estimated by the engineering treatment model for plane stress tension, Fracture Mechanics, vol. 24, pp. 635-651.

17-"ZENCRACK software version 7.9" ZENTECH.CO.

18-"CRACKWISE software version 5", TWI company.

19- Cosham, A., (2008), ECAs: Are they fit-forpurpose ?, Amsterdam, The Netherlands, 27-28 February, vol. 44, pp, OPT

20- Zhang, Y. M., Xiao, Z. M., Zhang, W. G., Huang, Z. H., (2014), Strain-based CTOD estimation formulations for fracture assessment of offshore pipelines subjected to large plastic deformation, journal of Ocean Engineering, vol. 91, pp. 64-72.

21- DNV-RP-F108, (2006), Fracture control for pipeline installation methods introducing, Det Norske Veritas.

22-"ABAQUS standard code version 6.14".

23- Yong-yi, W., Liu, M., (2012), Tensile Strain Models for Strain-Based Design of Pipelines, International Conference on Ocean, Offshore and Arctic Engineering,Rio de Janeiro. 